\title{
NUMISMÁTICA OMEYA ORIENTAL Y DE AL-ANDALUS
}

\author{
Pedro Cano Ávila \\ Universidad de Sevilla
}

\begin{abstract}
Orthodox caliph 'Umar emitted the first Muslim currencies. These had religious inscriptions..The coins of gold and copper of the Byzantine Empire, and the coins of silver of the Sasanian Empire were imitated. Later, the fifth Umayyad caliph, Abd al-Malik b. Marwan, reformed the Islamic monetary system. The new types of currencies were coined in all the Islamic Caliphate, and also in al-Andalus. The reproduction of people, animals and stellar elements disappeared of the coins. The inscriptions, the weight and the module of the currencies also were systematized for the whole epoch of the dynasty Umayyad.
\end{abstract}

\section{LOS PRIMEROS PASOS DE LA NUMISMÁTICA ISLÁMICA}

Cada vez se hace más necesario el acercamiento a la civilización arabo-islámica y su estudio, tanto de los siglos pasados y de su presencia y esplendor en la Península Ibérica, llamada en aquel tiempo en la mayor parte de su extensión geográfica al-Andalus, como en el presente, iniciado ya el siglo XXI. La mezcla de elementos culturales y la mutua comprensión y conocimiento son razones suficientes para continuar con esta labor, también en el campo de la investigación universitaria. Un tema muy atractivo es el de la numismática árabe oriental y el de la andalusí, ejemplos muy válidos del poder económico y cultural de los musulmanes de siglos pasados.

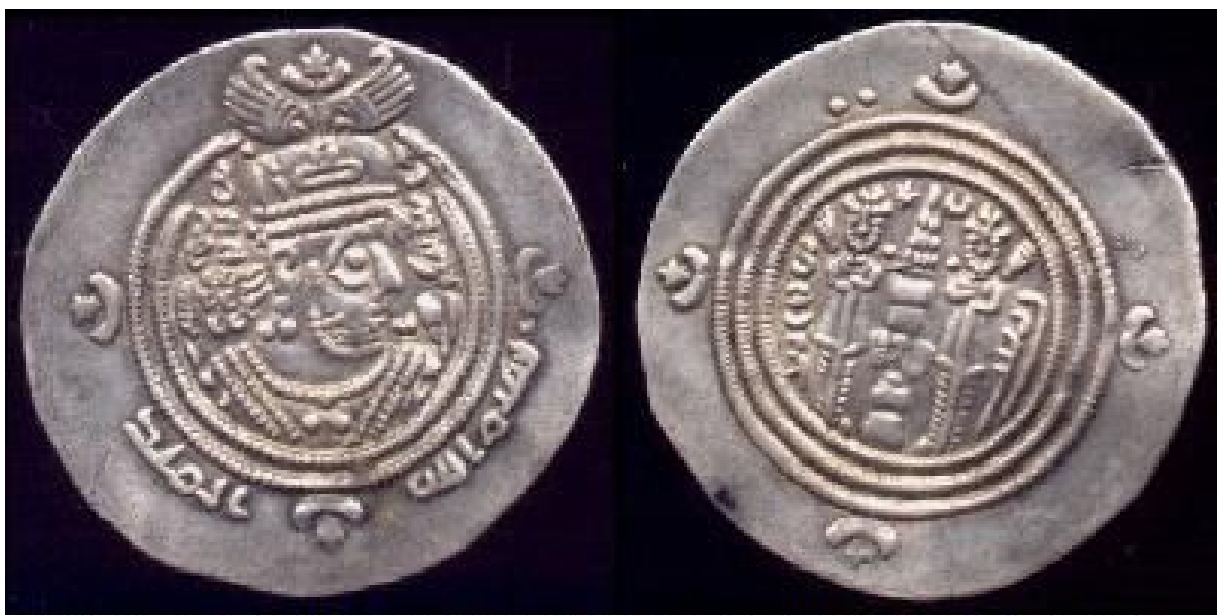

MONEDA ISLÁMICA QUE IMITA LA SASÁNIDA TIPO COSROES 
El primer Estado islámico fue establecido en el año 622 de J.C., que fue el primer año de la Hégira, es decir, de la huida del Profeta Muhammad de la ciudad de Meca a la de Medina. Algunos años después fue troquelada bajo el mandato del segundo califa ortodoxo, ${ }^{\mathrm{C}} \mathrm{Umar}$ Ibn al-Jattāb, en el año 18 de la Hégira (630 JC.), la primera moneda legal islámica -el dirham. Esa fue la unidad de plata del sistema numismático islámico, pesaba 2,97 gramos y tenía inscrita la leyenda árabe "Alabado sea Dios, Muhammad es su Profeta" cuyo estilo era cúfico arcaico. Imitaba la moneda de plata sasánida que circulaba en aquella época. En posteriores emisiones la leyenda fue "No hay más dios que Él" y también en otras monedas apareció inscrito en árabe el nombre del califa, 'Umar. Estas inscripciones cambiaban espontáneamente y no estaban sujetas a ningún sistema estricto ni establecido.

Después de la muerte del califa 'Umar otros califas emitieron monedas con la leyenda religiosa conocida por Kalima, es decir, la frase siguiente: "lā ilāh illà Allāh wahda-hu la šarīk la-hu” (لا اله الا الهه وحده لا شريك له له ), cuyo significado es: "No hay más dios que Alá, el Único, no hay ningún dios que asociarle". A veces aparece acuñado el nombre del gobernador bajo cuyo mandato se ordenó troquelar la moneda en cuestión y, para terminar, se inscribía la ceca y la fecha de acuñación según el cómputo de la Hégira.

Los musulmanes también troquelaron monedas de oro y de cobre a imitación de las bizantinas en numerosos talleres de acuñación, es decir, cecas del antiguo territorio dominado por el emperador bizantino.

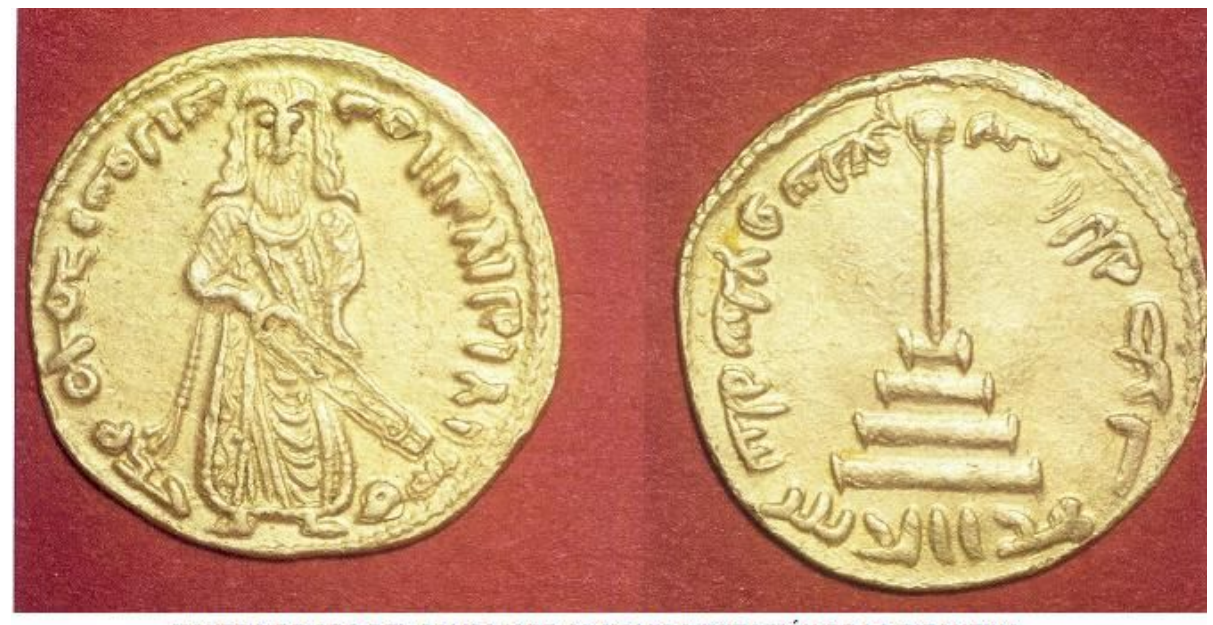

MONEDA DE ORO DEL CALIFA 'ABD AL-MALIK A IMITACIÓN DE LA BIZANTINA

Con el paso del tiempo, la expansión del imperio o califato islámico y el desarrollo de su comercio y primitiva industria exigieron establecer un sistema monetario más estable y uniforme. Se dejaron de acuñar poco a poco las primitivas monedas islámicas que imitaban las persa-sasánidas y las bizantinas que circulaban por los territorios conquistados por los musulmanes. El quinto califa omeya, llamado ${ }^{c} \mathrm{Abd}$ al-Malik ibn Marwan, decidió reformar el sistema numismático existente y establecer un nuevo sistema más moderno, uniforme y riguroso. Este sistema monetario estaba dotado de tres tipos de moneda ajustados a un diseño, peso, dimensión y ley metálica determinados que debían ser acuñados en adelante en 
todas las cecas del califato o imperio musulmán. Por consiguiente, ${ }^{\mathrm{c}} \mathrm{Abd}$ al-Malik designó como primera ceca -o como ceca más importante- la de Damasco, capital de su califato, en el año 77 de la Hégira / 695 JC., y allí fueron batidos el primer dinar -moneda de oro- y el primer dirham -moneda de plata- de la posreforma numismática. Esto conllevó la retirada de todas las demás monedas que con anterioridad habían circulado en el territorio musulmán. A partir de ese momento también se troquelaron nuevos feluses -monedas de cobre- que constituyeron el tercer tipo de moneda islámica y el de menos valor económico.

La islamización del sistema monetario fue muy importante, es decir, el hecho de que las únicas inscripciones que aparecieran en ambas áreas del cospel o flan fueran religiosas o estuvieran relacionadas con el Islam tuvo una suprema importan-cia. El citado califa ${ }^{\mathrm{c}} \mathrm{Abd}$ al-Malik prohibió la aparición de nombres de personas, o dicho de otra manera, se determinaron los textos que debían se acuñados, en los que no aparecía ningún nombre de persona, ni siquiera el del califa. Por lo tanto, estas monedas se convirtieron en anónimas. El nombre del califa no volvió a aparecer hasta comienzos de la época abbasí, en la segunda mitad del siglo VIII J.C. El que sí apareció fue el nombre de Dios, y varias veces en ambas áreas, las cuales presentaban dos leyendas en cada una de sus áreas -anverso y reverso. Una de estas leyendas se ubicó en el centro o campo en varias líneas rectas horizontales, y otra en la orla o en exergo de forma circular. Tales inscripciones religiosas habían sido obtenidas del Libro sagrado islámico, el Corán. A partir de entonces las monedas islámicas dejaron de mostrar figuras humanas, animales y astros, aunque varios siglos después aparecieron de nuevo en Oriente.

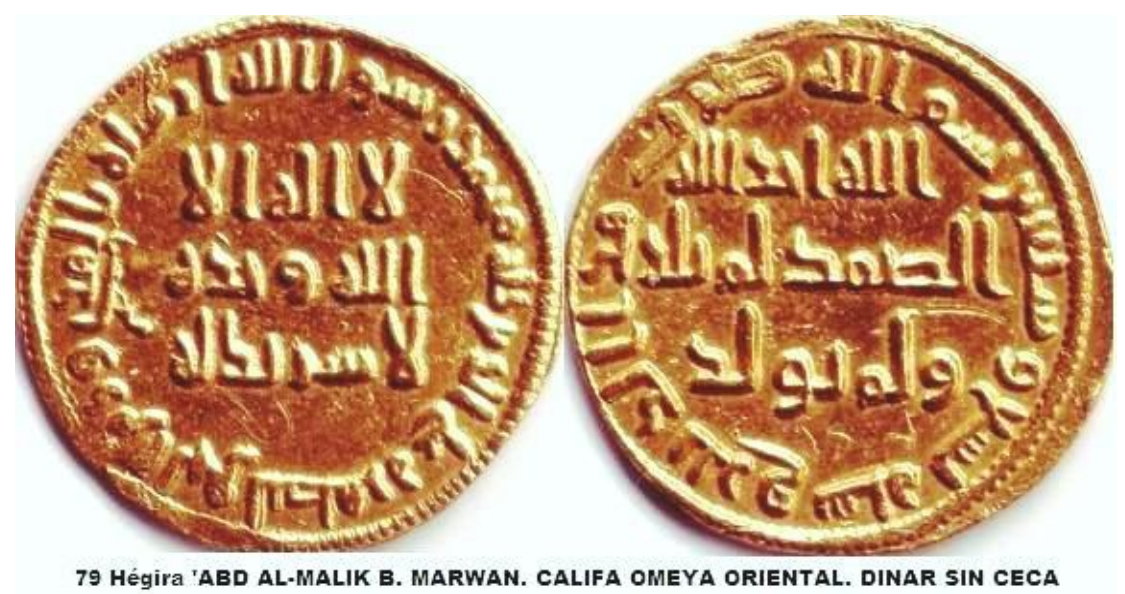

Las inscripciones del campo fueron dispuestas en tres líneas horizontales tanto en el anverso como en el reverso y se leen de derecha a izquierda. En cambio, las leyendas de la

${ }^{1}$ G. C., Miles, The Coinage of the Umayyads of Spain, (Hispanic Numismatic Series, Monograph $\mathrm{n}^{\circ}$ 1.), 2 vols. Nueva York, 1950; S. Lane-Poole, Catalogue of Oriental Coins in the British Museum, 10 vols. Bolonia, 1967-1969; M. Mitchiner, Oriental Coins and their values, vol. I: The World of Islam, Londres, 1977; S. M. Stern, Coins and Documents from the Medieval Middle East, Londres, 1986; M. Broome, A handbook of Islamic coins, Londres, 1985; N. M. Lowick, Islamic Coins and trade in the Medieval World, (Collected Studies Series No. 318.), ed. Joe Cribb, Aldershot, 1990 
orla se disponen de forma circular y suelen comenzar a las dos o a las tres horas, tomando como referencia la esfera circular de un reloj. Su estilo epigráfico fue el cúfico arcaico.

Como puede observarse, pues, el sistema numismático islámico estaba basado en tres tipos de metales a los que correspondían lógicamente tres valores económicos diferentes. Era un sistema trimetálico, aunque no siempre se acuñaron, ni en todas las regiones, monedas con esos tres metales. Hubo áreas en Oriente que se especializaron en emisiones de monedas de plata -dirhames o dírhemes- basadas en los dracmas sasánidas. Esas regiones venían a corresponder con las antiguas provincias persa-sasánidas, hoy en parte de Iraq y en Irán. Otras zonas cultivaron las monedas de oro, es decir, los dinares, con sus respectivos divisores como los semidinares y los tercios de dinar y, además, las monedas de cobre, es decir, los feluses. Los dinares procedían de los antiguos sólidos -solidus bizantino-y sus divisores -los semidinares y los tercios de dinar- de los equivalentes divisores bizantinos, es decir, de los semises y tremises o trientes bizantinos. En el califato musulmán las cecas especializadas en la acuñación de dinares y feluses estaban ubicadas en territorios antes dominados por los bizantinos, o sea, en territorios de los actuales Israel, Palestina, Siria, Iraq y Jordania. Los musulmanes imitaron de esta manera las monedas que conocieron y usaron en las tierras conquistadas al norte de la Península Arábiga. El emir, o en su caso el califa, tenía el privilegio y el derecho de acuñar moneda y de determinar todas sus características. Él era el único dotado de este privilegio. Si alguien osara acuñar moneda estaría evidenciando su insumisión, su rebeldía y, en consecuencia, se vería sometido a persecución y castigo. Pero no es éste el caso de profundizar más en estas circunstancias y en otros detalles, pasemos a al-Andalus.

\section{Los musulmanes en la Península Ibérica}

Nos acercamos ahora al área de Hispania en su etapa visigótica. Es la zona que más nos interesa. Se trata de una zona un tanto especial, desde el punto de vista numismático, porque los musulmanes llegados a este territorio no imitaron totalmente las monedas que circulaban por el territorio peninsular, como cabría esperar. Ésas eran de tipo bizantino y de tipo visigótico. Las primeras monedas troqueladas fueron tremises o trientes de oro -un divisor o moneda fraccionaria del solidus bizantino- y bronces bizantinos acuñados tanto en Cartagena, como en el Norte de África, especialmente en Cartago (hoy en Túnez), por lo tanto, estaba en vigor un sistema bimetálico. Las segundas, es decir, las piezas de tipo visigótico, en cambio, imitaron en un principio las del Imperio romano y, más tarde, se crearon nuevas monedas ajustadas al gusto y necesidades del momento.

Hasta hace pocos años se ha insistido en que los visigodos solamente acuñaron tipos de monedas de oro, pero en estas dos últimas décadas se ha afirmado que también se manufacturaron monedas de cobre, e incluso algunas de plata. Las cecas visigóticas eran Cartagena, Toledo, Mérida e Ispali (Hispalis). Hay escasos ejemplares de este numerario.

En Hispania las primeras monedas troqueladas por los musulmanes no fueron a imitación de las visigóticas circulantes, como ha demostrado entre otros M. L. Bates y A. M. Balaguer ${ }^{2}$. Hicieron caso omiso a ese numerario, entre otras razones, porque las autoridades musulmanas trajeron a Hispania operarios especializados en la acuñación numismática, seguramente de la ceca norteafricana de Cartago.

${ }^{2}$ Véase A. M. Balaguer, Las emisiones transicionales árabe-musulmanas de Hispania, Barcelona, 1976, con láminas. 


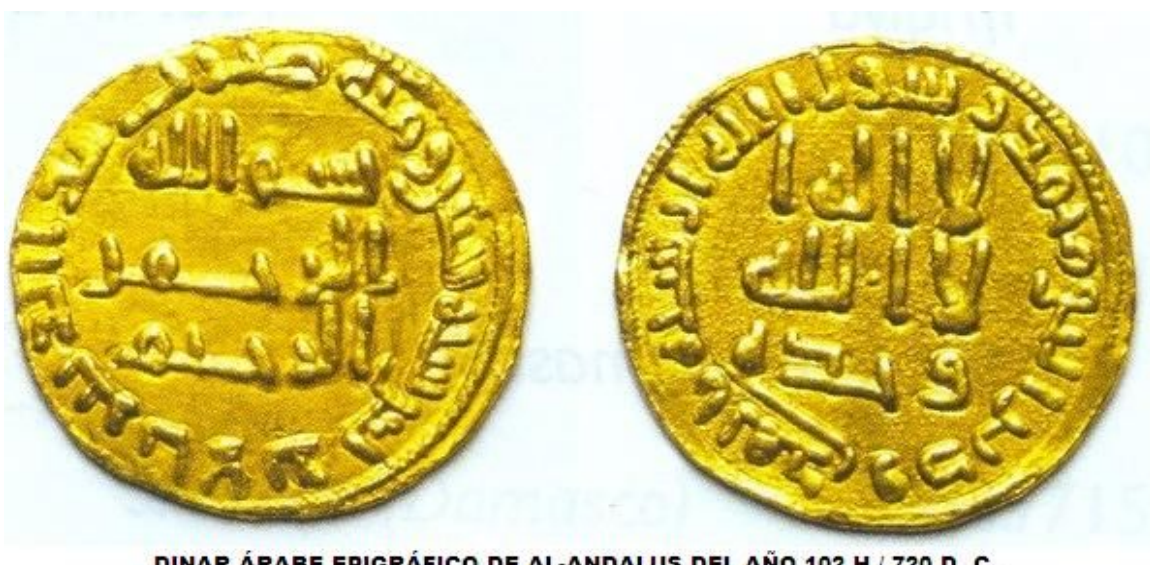

En al-Andalus -nombre actualizado del territorio antes llamado Hispania- como en otras regiones del califato islámico, hubo épocas en las que sólo se acuñaron monedas de oro y cobre, otras épocas en las que se troquelaron monedas de plata y, finalmente, otras en las que sólo se batieron monedas de oro y plata. A veces, la aleación metálica no se ajustaba a la normativa establecida por el califa omeya ${ }^{c} A b d$ al-Malik y se empleaba menos metal precioso en las cecas para la elaboración de monedas, lo que suponía un fraude económico. Esto era frecuente en épocas de crisis política. Por ejemplo, en la época posterior al califato de la dinastía Omeya de al-Andalus, es decir, en la época de los primeros reinos de taifas, se manufacturaban monedas de oro de baja ley metálica, conocidas por dinares de electro o electrón, y monedas de plata también de baja ley metálica, conocidas por dírhemes de vellón.

En la taifa de Sevilla del siglo XI d.C. se acuñaron muchos dinares de buena ley, hecho excepcional en aquella época, puesto que en la gran mayoría de reinos de taifas se acuñaban dinares, o sus divisores, de electrón y también se acuñaron dírhemes, o fracciones de dírhem, de vellón. Incluso sucedió algo peor en al-Andalus en varias ocasiones, como fue la troquelación de dírhemes con alma de cobre y baño de plata, y con cospeles de menor tamaño y forma irregular, lo que dejaba mucho que desear tanto en la calidad como en el aspecto de esas monedas.

La caligrafía o epigrafía que exhibieron estas monedas también presentó una figura y un diseño generalmente deteriorados. Era, por lo general, descuidada, aunque a veces se manufacturaron verdaderas preciosidades, como sucedió en algunas monedas de plata de la época califal realizadas en estilo cúfico florido, es decir, con adornos y detalles en los extremos de algunas consonantes más apropiadas al adorno de carácter fitomórfico. Esto también sucedió en la época almorávide, algunas de cuyas monedas presentaron leyendas realizadas en habilísimo y sinuoso estilo nasjí. 


\section{Clasificación de la numismática islámica de al-Andalus}

Llegados a este punto lo mejor es ofrecer una somera clasificación de la numismática realizada y desarrollada en al-Andalus. Es frecuente clasificarla según la dinastía gobernante, es decir, a teniéndose a la situación político-militar del territorio. Tal vez sea la forma más clara, simple y directa. Existen los siguientes grupos:

1. Numismática andalusí transicional. De oro y cobre. Principios del siglo VIIP.

2. Numismática del emirato dependiente de Oriente. De oro, plata y cobre. $1^{\mathrm{a}} \mathrm{mitad}$ siglo VIII ${ }^{4}$.

3. Numismática del emirato omeya de al-Andalus, independiente de Oriente. De plata y cobre. Siglos VIII-X

4. Numismática del califato andalusí. De oro y plata. Siglos X-XI'.

5. Numismática de los primeros reinos de taifas. De oro y plata, aunque de baja ley. Siglo $\mathrm{XI}^{7}$.

6. Numismática almorávide. De oro y plata. De buena ley metálica. Siglos XI-XII.

7. Numismática almohade. De oro y plata. De buena ley. Siglos XII-XIII?.

8. Numismática nazarí. De oro, plata y cobre, aunque de baja ley. Siglos XIII-XV'10.

3 A. M. Balaguer, "Las emisiones transicionales arabe-musulmanas de al-Andalus: Nueva Síntesis",I. Jarique de Estudios Numismáticos Hispano-Arabes, Zaragoza, 1988, 11-28; A. M. Balaguer, "Early Islamic Transitional Gold Issues of North Africa and Spain in the American Numismatic Society", ANS Museum Notes, 24 (1979), 225-241.

${ }^{4}$ P. Cano Ávila, "Monedas orientales de época musulmana halladas cerca de Alcaudete (Jaén)", Boletín de la Asociación Española de Orientalistas (BAEO), XXVI (1990), 215-231; P. Cano Ávila, "Algunos dírhemes hallados cerca de Alcaudete (Jaén)", VII Congreso Nacional de Numismática. Memoria, Madrid, 1991, 489-504; F. Martín Escudero, El Tesoro de Baena. Reflexiones sobre circulación monetaria en época omeya Madrid, 2005, 16-22, 33-44; M. Barceló, "Sobre algunos 'fulus' contemporáneos de la conquista de Hispania por los árabes-musulmanes", Boletín de la Real Academia de Buenas Letras de Barcelona, XXXIV (1971-72), 33-42; M. Bates, "The Coinage of Spain Under the Umayyad Caliphs of the East, 711-750", III Jarique de Numismática Hispano-Árabe, Madrid, 1990, 271-289.

${ }^{5}$ G. C. Miles, The Coinage of the Umayyads of Spain, 131-234. Es la parte dedicada al emirato omeya de alAndalus; A., Canto García, "El periodo Omeya. El Emirato. La aparición de la tipologia califal. 'Abd al-Rahman III: Sus sucesores”, I Jarique de Estudios Numismáticos Hispano-Árabes, Zaragoza, 1988, 29-41.

${ }^{6}$ G. C. Miles, The Coinage of the Umayyads of Spain, 235-549. Se trata de la parte del califato omeya de alAndalus.

${ }^{7}$ A. Prieto y Vives, Los Reyes de Taifas. Estudio histórico-numismático de los musulmanes españoles en el siglo $V$ de la Hégira (XI d. de J.C.), Madrid, 1926, 30-279; A., Canto García, "La moneda", en M. J. Viguera (coord. y pról), Los Reinos de Taifas. Al-Andalus en el siglo XI, vol. VIII-I, de la Historia de España Menéndez Pidal, Madrid, 1999, 275-297; P. Guichard, "Quelques réflexions sur le monnayage des premières Taifas andalouses (1009/400-1059/451)», II Jarique de Estudios Numismáticos Hispano-Árabes, Lérida, 1990, 155-161.

${ }^{8}$ H. E. Kassis, "La moneda, pesos y medidas", en M. J. Viguera (coord. y pról), El retroceso territorial de alAndalus. Almorávides y Almohades. Siglos XI al XIII, vol. VIII-II, de la Historia de España Menéndez Pidal, Madrid, 1997, 301-337, en concreto, 301-321 (Citaré Kassis, Moneda). A. Vives y Escudero, Monedas de las dinastías arábigo-españolas, Madrid, 1998; H. W. Hazard, The Numismatic History of the Late Medieval North Africa, Nueva York, 1952.

9 Kassis, Moneda, 322-329, aunque las notas al final del capítulo están en las páginas 332-337 y las correspondientes a la numismática almohade en las páginas 336-337; J. D. Brèthes, Contributions à l'histoire du Maroc par les recherches numismatiques, Casablanca, 1939.

${ }^{10}$ S. Fontenla Ballesta, "Un intento de sistematización de la plata nasrí", I Jarique, 141-146; del mismo, "El cobre nazarí", Numisma, 232 (enero-junio, 1993), 163-175; J. J. Rodríguez Lorente, Numismática nasrí, Madrid, 1983; F. Codera y Zaidín, Tratado de numismática arábigo-española, Madrid, 1879, 231-240; G. Roselló Bordoy, "II. La moneda", en M. J. Viguera (coord. y pról.), El reino nazarí de Granada (1232-1492). Politica, instituciones. 


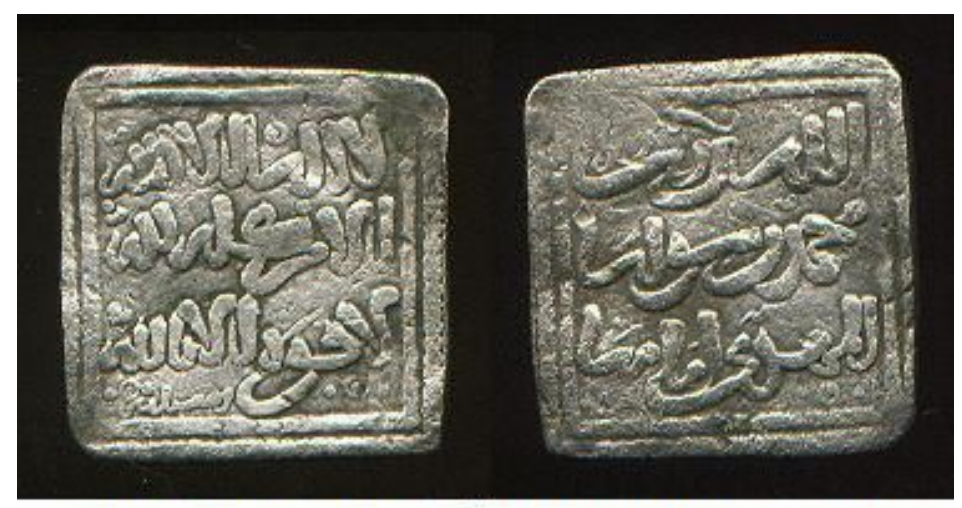

DIRHAM ALMOHADE ACUÑADO EN SEVILLA. S. XII JC

De estos ocho grupos los cuatro primeros se desarrollaron bajo el mandato de la dinastía omeya, ya fuera en Oriente, ya fuera en al-Andalus. Los grupos quinto y sexto fueron deudores de la numismática anterior, es decir, que trataron de continuar con las características fundamentales de la numismática omeya. Pero ya en este grupo sexto y, sobre todo, en el séptimo y octavo las características formales y sus leyendas dieron muestra de un cambio casi radical de la acuñación de monedas en al-Andalus en sus formas y en su contenido.

\subsection{Características de la numismática andalusí ${ }^{11}$}

Por la forma del flan o cospel de las monedas podríamos clasificarlas en circulares o cuadradas. También hay monedas que son mixtas, es decir, que tienen un cospel circular, pero con un cuadrado en su interior que recuerda la moneda de formato cuadrado. La inmensa mayoría de las monedas troqueladas en al-Andalus es circular, en todos los siglos de presencia musulmana, y la casi imperceptible minoría es cuadrada. Monedas con flan circular -o con forma irregular pero aproximándose al flan circular- fueron las troqueladas en al-Andalus desde la llegada de los musulmanes, a principios del siglo VIII, hasta la reforma numismática de los almohades, a mitad del siglo XII. Son cuadradas algunas monedas de plata, dírhemes y sus divisores, acuñadas por los almohades. Después, algunos rebeldes andalusíes y la dinastía nazarí, titular del reino de Granada, imitaron tales piezas cuadradas. Sin embargo, son mixtas algunas monedas acuñadas por los almohades y por autoridades posteriores, como las nazaríes.

Por las leyendas que están acuñadas en ambas áreas también se pueden clasificar las monedas andalusíes, teniendo también siempre en cuenta que los gobernantes, o mejor aún, las dinastías son las que establecen esas inscripciones, su contenido, ubicación y carácter. Las más importantes inscripciones son las religiosas. En todas las épocas se presentan aleyas extraídas del Corán, siempre en el anverso y muchas veces también en el reverso. Con éstas se quiere marcar la diferencia entre los musulmanes y quienes no lo son, y la ideología o el matiz predominante en cada dinastía e incluso en cada gobernante, siendo

Espacio y economía, vol. VIII-III, de la Historia de España Menéndez Pidal, Madrid, 2000, 565-582.

${ }^{11}$ A. Medina Gómez, Monedas Hispano-Musulmanas. Manual de lectura y clasificación, Toledo, 1992. 
todos ellos musulmanes. La leyenda favorita es la llamada kalima, consistente en asegurar que "no hay más dios que Él, el Único, no hay ningún dios que asociarle". Manifiestan por encima de todo la unicidad divina del dios musulmán.

En la segunda parte del emirato andalusí dependiente de Oriente y durante toda la época omeya y los reinos de taifas -siglos VIII al XI JC- hubo una leyenda, situada en la orla, que mostraba datos históricos, como fueron el nombre de la moneda -dinar, dírhem o felús-, el nombre de la ceca y el año de acuñación ${ }^{12}$. Esa buena costumbre se empezó a perder con los almorávides y los almohades. Los nazaríes acostumbran a no poner la ceca ni la fecha de acuñación, en escasas ocasiones grabaron tales datos. Esto ha dificultado mucho la correcta datación de las monedas, claro está.

En al-Andalus quienes dieron un giro considerable a la numismática islámica fueron, en primer lugar, los califas omeyas descendientes de su antepasado, el primer emir omeya andalusí, 'Abd al-Rahman I. Lo hicieron para hacerse notar en relación con épocas anteriores desde el punto de vista político, porque introdujeron sus nombres y títulos. En segundo lugar, los almorávides, por sus novedades religiosas en las inscripciones y por el empleo del estilo nasjí junto al estilo cúfico de siempre; y en tercer lugar, los almohades, por las formas cuadradas de algunas de sus monedas, por sus inscripciones religiosas novedosas y por la inclusión de la genealogía del califa gobernante, y no sólo del nombre. Los nazaríes prácticamente fueron continuadores de las características de la numismática almohade.

En cuanto a los talleres de acuñación y con voluntad de resumir lo más posible, su número y la calidad de las monedas en ellos batidas fue muy variable. El nombre del taller de acuñación, es decir, de la ceca usada por los primeros musulmanes fue el de Hispania, determinado como SPN o SPAN. Se inscribió en monedas de grafía latina y en el período de los años 712 al 714 d.C., probablemente la ubicación del taller estaría en Toledo o en Sevilla. Más tarde en el año 98 de la Hégira/716-717 d.C. surgió por primera vez el nombre de al-Andalus en una moneda y ésta constituyó el primer vestigio escrito de este nombre, que ya se conservaría hasta finales del siglo XV y después en toda clase de documentos históricos. Esa moneda fue bilingüe, sus lenguas eran latina en el anverso y árabe en el reverso. La ceca sería quizá Sevilla.

Al trasladarse la sede del gobierno de Sevilla a Córdoba en la época de los gobernadores dependientes del emir de Qayrawán, en Túnez hoy día, la ceca también sería trasladada a Córdoba. Con la toma del poder por parte del omeya ${ }^{\mathrm{C}} \mathrm{Abd}$ al-Rahman I y durante todo el emirato, es decir, casi dos siglos, la ceca continuó con la denominación al-Andalus y se encontraba cerca del alcázar de Córdoba. Después, en el califato omeya andalusí se creó una ceca nueva que se ubicó en Medina Azahara, funcionó alrededor de treinta años y sustituyó a la de al-Andalus ${ }^{13}$. En el Norte de África otras cecas también acuñaron moneda en la época del califato andalusí y bajo su soberanía, como por ejemplo Ceuta, Fez, Nakur, Siyilmasa y al-Mansura.

\footnotetext{
${ }^{12}$ P. Cano Ávila, "Dirhemes califales hallados cerca de Alcaudete (Jaén)", III Jarique de Numismática HispanoÁrabe, Madrid, 1990, 299-311. Véase además en Internet: http://stevealbum.com/ y http://www.islamiccoinsgroup.50g.com/ (07-04-2006)

${ }_{13}$ R. Frochoso Sánchez, Las monedas califales de ceca al-Andalus y Madinat al-Zahra', 316-403 H. 928-1013 J.C., Córdoba, 1996, 11-17; A. Canto García, El periodo Omeya, 29-41.
} 


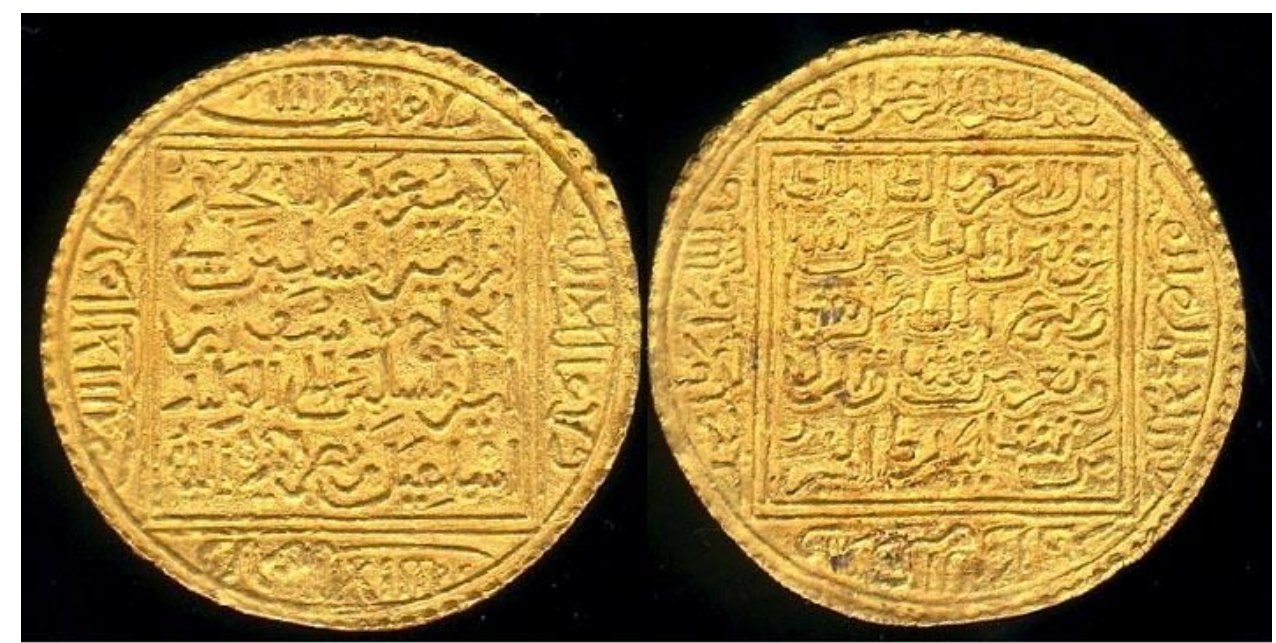

DINAR COMPLETO, O DOBLA, DEL SULTÁN NAZARí dE GRANADA MUHAMMAD V, 2' MITAD S. XIV JC

En el califato omeya de Córdoba los dinares pesaron unos 4,25 gr., aunque oscilaba de 3,6 a 5 grs., y un módulo de 22 a $23 \mathrm{~mm}$. aproximadamente. Por su parte, los dírhemes, es decir, las monedas de plata, tenían aproximadamente un módulo de 22 a $23 \mathrm{~mm}$. y un peso que variaba de 2,44 a 5,34 gr., aunque le frecuente es que pesaran en torno a 2,7 gr. No había apenas diferencias con monedas del Norte de África o de Oriente.

No se debe terminar sin insistir en que la importancia e influencia de la numismática islámica y de la islámica andalusí está demostrada por su calidad metálica, la riqueza de sus inscripciones y también por las imitaciones cristianas de la época. Como ejemplo de imitaciones podemos citar los maravedíes del rey de Castilla y León Alfonso VIII, troquelados en el primer tercio del siglo XIII d. C. en la ceca de Toledo. 